\title{
Superior Laryngeal Nerve Response Patterns to Chemical Stimulation of Sheep Epiglottis
}

\author{
ROBERT M. BRADLEY ${ }^{1,2,{ }^{*}}$ HAZEL M. STEDMAN ${ }^{1}$ and CHARLOTTE M. MISTRETTA ${ }^{1,3}$ \\ ${ }^{1}$ Department of Oral Biology, School of Dentistry University of Michigan, Ann Arbor, MI 48109, ${ }^{2}$ Department of Physiology, \\ School of Medicine, University of Michigan, Ann Arbor, MI 48109, and ${ }^{3}$ Center for Human Growth and Development, and The \\ Research Center, School of Nursing, University of Michigan, Ann Arbor, MI 48109 (U.S.A.)
}

(Accepted February 8th, 1983)

Key words: epiglottis — superior laryngeal nerve — chemoreception — neurophysiology — sheep

\begin{abstract}
Responses were recorded from single fibers of the sheep superior laryngeal nerve during stimulation of the epiglottis with $0.5 \mathrm{M}$ $\mathrm{KCl}, \mathrm{NH}_{4} \mathrm{Cl}, \mathrm{NaCl}$ and $\mathrm{LiCl}$, distilled water, $0.005 \mathrm{M}$ citric acid, and $0.01 \mathrm{~N} \mathrm{HCl}$. Recordings were made from both lambs and ewes. $\mathrm{KCl}$ elicited a response from $99 \%$ of fibers followed in order of effective stimulation by $\mathrm{NH}_{4} \mathrm{Cl}, \mathrm{HCl}$, distilled water, citric acid, $\mathrm{NaCl}$ and $\mathrm{LiCl}$. Analysis of the variation in response frequency with time demonstrated differences in the response patterns for these stimuli. The pattern of frequency over time is sufficient to discriminate among the salts, between some of the salts and acids, and between some of the salts and water. Therefore the response pattern may be significant in initiating the various reflex activities that occur during chemical stimulation of the larynx.
\end{abstract}

\section{INTRODUCTION}

Sensory responses from the superior laryngeal nerve (SLN) have been studied to investigate, primarily, the neural mechanisms underlying upper airway reflexes. For example, tactile, gaseous, acidic and osmotic stimuli have been applied to the larynx and epiglottis because such stimuli are known to elicit the upper airway reflexes of coughing, swallowing and apnea ${ }^{3}$. Electrophysiological responses from SLN fibers have been recorded to learn how neural activity is related to these various types of stimuli and, thus, to the various reflexes 24.25 .

Interestingly, initial studies revealed a remarkable diversity of neural response characteristics ${ }^{1,24}$. Storey ${ }^{24}$ attempted to describe fibers by types, based on responses to mechanical and chemical stimuli. However, the types he defined were far from homogeneous and he therefore concluded that a continuum of response characteristics exists across SLN fibers.

Since the epiglottis has many taste buds ${ }^{6}$, it is cu- rious that taste scientists have virtually ignored the study of chemosensitive responses from the SLN. Recently, however, Stedman et al. 23 investigated chemosensitive fibers supplying epiglottal taste buds in cats, using a variety of salt and acid stimuli, and concentration series of chemicals. They concluded that responses recorded during chemical stimulation of the epiglottis were similar to those recorded during chemical stimulation of the tongue. However, no new insights emerged on a general scheme for categorizing or classifying fibers according to chemical responses.

It may be that previous attempts to classify SLN responses to chemical stimuli have been impeded by a rather narrow approach to data analysis. Although measures of response latency 12.23 and time to peak frequency ${ }^{23}$ have been incorporated by some investigators in analysis of the neural discharge, the overall pattern of the response has never been studied. We have taken this latter approach in an attempt to understand better the chemosensitive responses from the SLN.

\footnotetext{
* Send correspondence to: Dr. Robert M. Bradley, Department of Oral Biology, School of Dentistry, University of Michigan, Ann Arbor, MI 48109, U.S.A.
} 
In both the lamb and adult sheep the structure and number of taste buds on the epiglottis have been described ${ }^{6}$. and there is information on reflex responses to chemicals applied to the larynx ${ }^{13}$. Consequently, we have used lambs and ewes for neurophysiological studies of SLN responses. Furthermore, we have extensive data on responses to chemical stimulation of lingual taste buds supplied by the chorda tympani and glossopharyngeal nerves in the sheep, and so neural activity from the three nerves in response to the same chemical stimuli can be compared 5 .

\section{MATERIALS AND METHODS}

\section{Surgical preparation}

Twelve Dorset lambs (aged 30-70 days) and 5 adult ewes (aged 2-4 years) were kept in the laboratory for at least one week to ensure that they had no overt signs of respiratory infection. The animals were anesthetized with an intravenous injection of sodium pentobarbital ( $25 \mathrm{mg} / \mathrm{kg}$ for lambs; $30 \mathrm{mg} / \mathrm{kg}$ for ewes) and placed supine on an operating table. A tracheostomy was performed close to the sternal notch and the jugular vein was cannulated for administration of supplemental anesthetic. Lambs were wrapped in a heating pad adjusted to maintain rectal temperature at $39^{\circ} \mathrm{C}$.

To prevent reflex swallowing while recording from the right SLN, the left SLN was located and cut. A midline incision was made into the larynx, through the thyroid cartilage, without cutting the base of the epiglottis. The epiglottis was reflected into the larynx so that its laryngeal surface was exposed through the incision, and held in place with a suture ${ }^{23}$. The epiglottis was bathed with $0.154 \mathrm{M} \mathrm{NaCl}$ when not stimulated experimentally.

\section{Neurophysiology}

The right SLN was located and cut close to its junction with the vagus nerve. The connective tissue and sheath were dissected and the nerve was subdivided into small bundles of fibers for single unit recording. Bundles were placed on a platinum wire electrode and a reference electrode was positioned in nearby tissue. The neural activity was amplified, displayed on an oscilloscope and monitored with an audio amplifier. Neural data were stored on one channel of a magnetic tape recorder, with voice cues for experi- mental procedures on a second channel.

Recordings were made from 59 single fibers (30) lamb and 29 ewe units). Activity was classified as 'single unit' by examination of impulse amplitude and waveform in high speed photographic records of action potentials. Active epiglottal units were isolated by stroking the epiglottis with a small brush. If a mechanically sensitive unit was identified, chemicals were then applied $\left(\mathrm{KCl}, \mathrm{NH}_{4} \mathrm{Cl}\right.$ and water) to establish chemosensitivity. Thus all units responded to both tactile and chemical stimuli. Tactile units that were not chemosensitive were not analyzed further.

\section{Stimuli}

Chemical stimuli were $0.5 \mathrm{M} \mathrm{KCl}, \mathrm{NH}_{4} \mathrm{Cl}, \mathrm{NaCl}$ and $\mathrm{LiCl}, 0.005 \mathrm{M}$ citric acid $(\mathrm{pH}=2.76), 0.01 \mathrm{~N}$ $\mathrm{HCl}(\mathrm{pH}=2.00)$ and distilled water. The concentrations were chosen so that direct comparisons could be made with previously collected data on responses from sheep chorda tympani and glossopharyngeal nerves during chemical stimulation of the tongue. Since the presence of water on the epiglottis produces a neural discharge, all chemicals were dissolved in $0.154 \mathrm{M} \mathrm{NaCl}$ which elicits minimal activity; $0.154 \mathrm{M}$ $\mathrm{NaCl}$ was also used as the rinse solution. Chemical stimuli and rinses were applied at room temperature.

A gravity flow system was used to deliver $20 \mathrm{ml}$ of each stimulus and at least $50 \mathrm{ml}$ of rinse solution from a funnel. Chemicals remained on the epiglottis for 20 $s$ and were then rinsed until neural activity returned to baseline levels. Fluids were removed from the larynx via a tube inserted rostrally in the tracheostomy incision and connected to a suction pump and fluid trap.

The chemical stimulation sequence was always the same $\left(\mathrm{KCl}, \mathrm{NH}_{4} \mathrm{Cl}, \mathrm{NaCl}, \mathrm{LiCl}, \mathrm{KCl}\right.$, water, citric acid, $\mathrm{HCl}$, and $\mathrm{KCl}$ ). It was possible to apply this total sequence twice for $29 \%$ of the units. When chemicals were applied more than once, responses were averaged for that fiber. Since $0.5 \mathrm{M} \mathrm{KCl}$ was found to be an effective stimulus in preliminary experiments, it was chosen as a standard and applied 3 times in the stimulation sequence to monitor the stability of the preparation.

\section{Data analysis}

Recorded neural impulses were converted to standard electrical pulses with a window discrimina- 
tor and the time between the pulses in milliseconds was measured with a microcomputer ${ }^{4}$. Interpulse intervals were stored on magnetic disks and a program was then implemented to convert these intervals to frequency (impulses per second). Frequencies were measured before, during and after a stimulation period.
Before the final data analysis was performed both the spontaneous frequency and response frequency due to flow of fluid over the epiglottis were subtracted. Mean spontaneous activity was calculated for each fiber by averaging the frequency during the $5 \mathrm{~s}$ periods preceding each chemical stimulation. Flow response frequency was determined by averag-
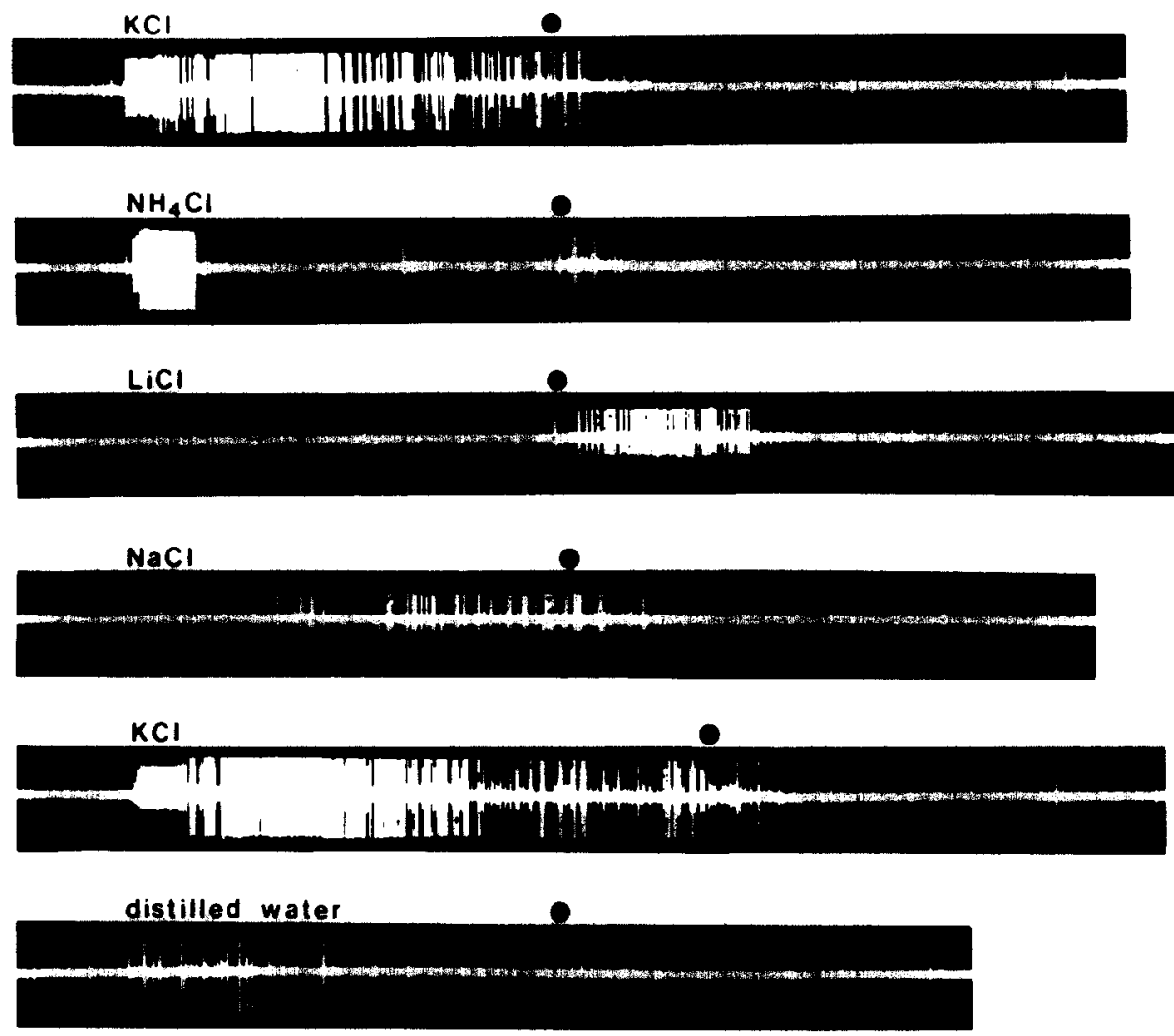

citric acid
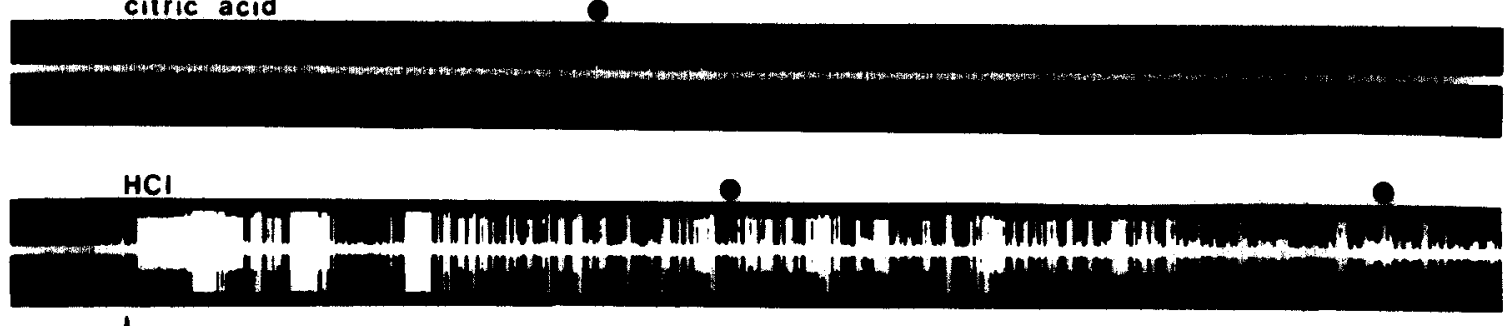

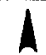

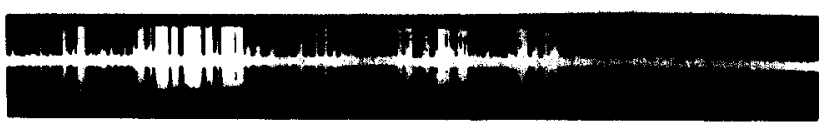

$5 \mathrm{sec}$

Fig. 1. Neurophysiological records from a large and small amplitude unit of the superior laryngeal nerve in a lamb during stimulation of the epiglottis with chemical stimuli. The arrow indicates the time of stimulus application and the dots indicate rinses. The large amplitude unit does not respond to $\mathrm{LiCl}$ and $\mathrm{NaCl}$. For each unit, the pattern of response frequency depends on the stimulus. For example, $\mathrm{KCl}$ elicits a sustained response, whereas the response to $\mathrm{NH}_{4} \mathrm{Cl}$ ceases before the stimulus is rinsed from the epiglottis. 
LAMB
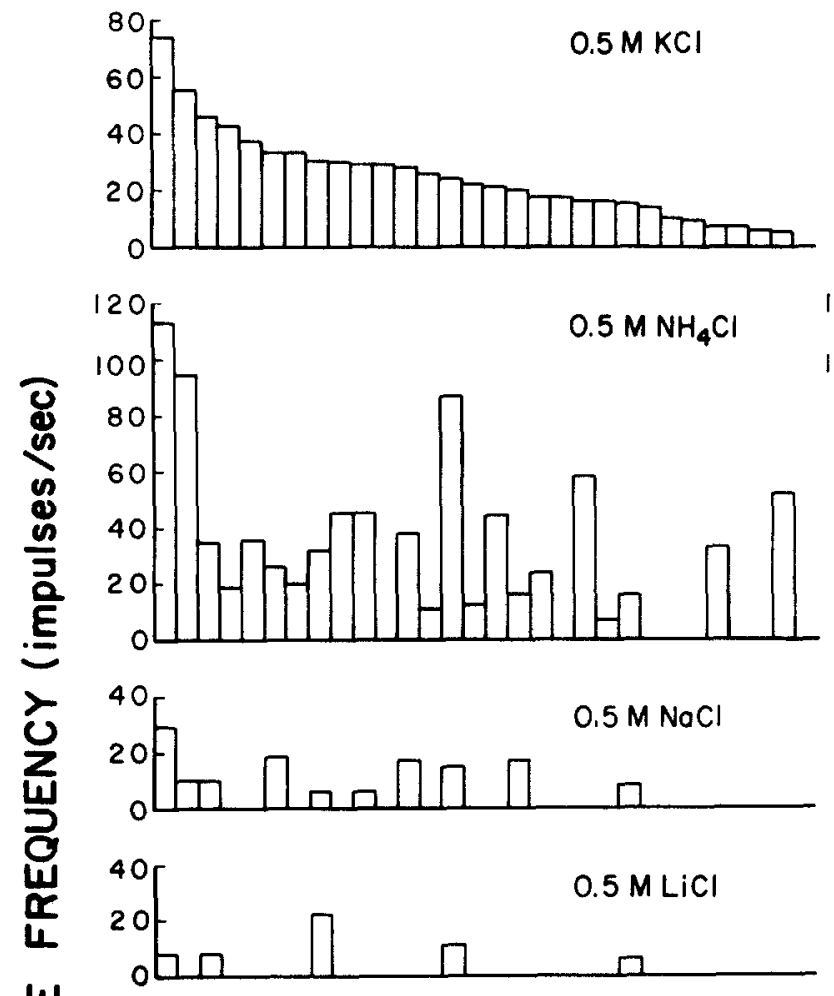

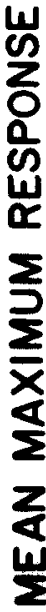
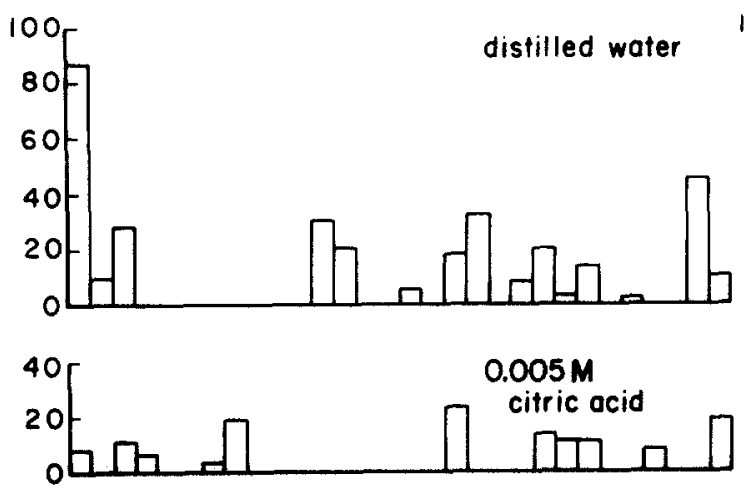
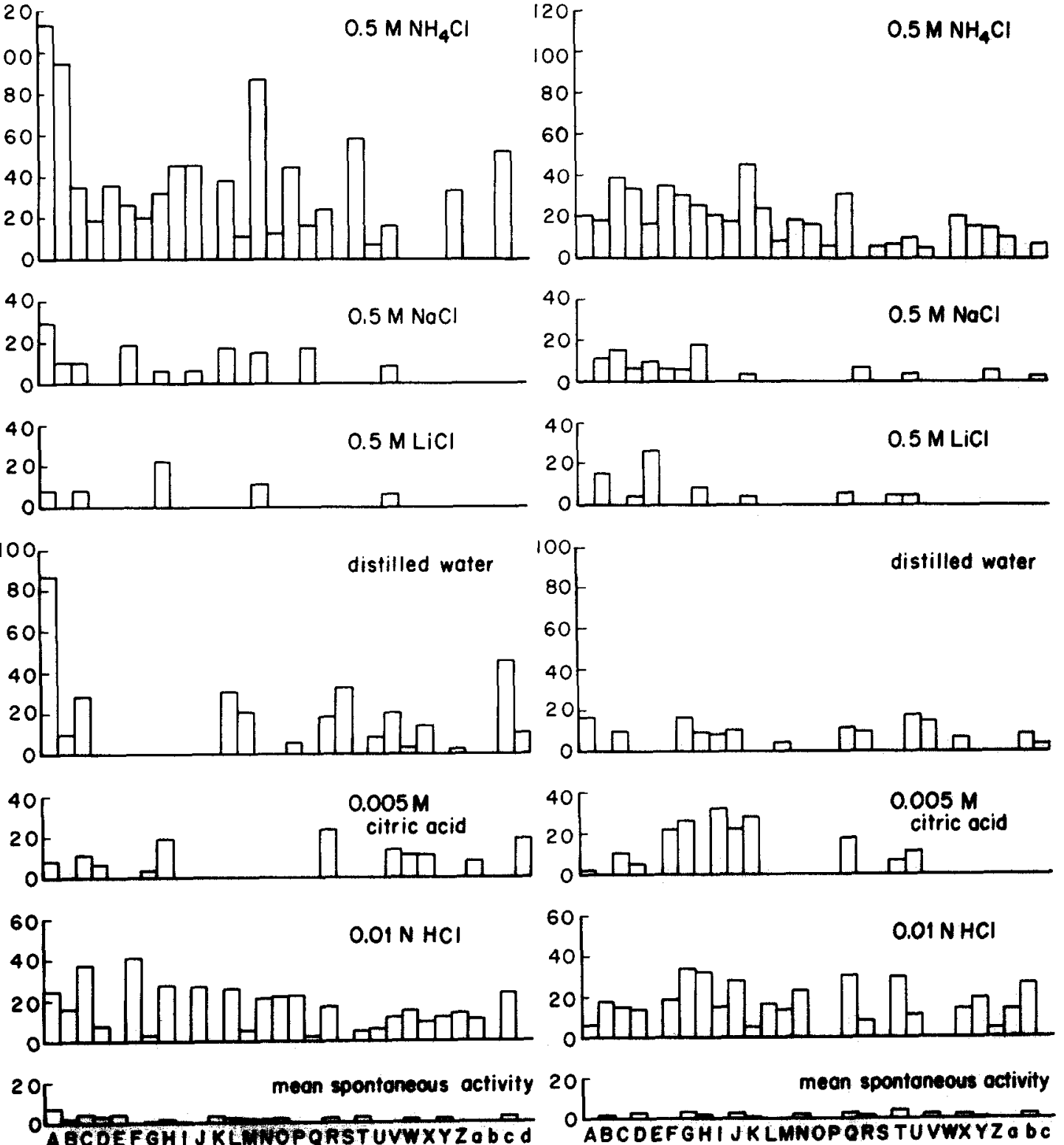

SINGLE FIBERS

Fig. 2. Maximum response frequencies from lamb and ewe single fibers for all the chemical stimuli. The units (A through d) have been ranked in order of the maximum response frequency fo $\mathrm{KCl}$. Therefore, responses for any one fiber to all chemicals can be read in a vertical column. Mean spontaneous activity (noted at the bottom of each column) and the response due to flow of the stimulus (impulses/s) have been subtracted, so the response to chemical stimulation only is presented. 
ing the frequency during $5 \mathrm{~s}$ periods when a rinse solution was delivered to the epiglottis. Therefore only activity in response to chemical stimulation was analyzed.

\section{Parameters measured}

Response characteristics vary among fibers, and within a single fiber, depending on the chemical stimulus. Fig. 1 illustrates responses recorded simultaneously from two single fibers that were easily separable on the basis of impulse amplitude. It is apparent from this figure that all fibers do not respond to all chemicals. For example, in Fig. 1 the large amplitude unit does not respond to $\mathrm{LiCl}$ and $\mathrm{NaCl}$. It is also apparent that when a response does occur, the frequency pattern during the entire response period depends on the particular chemical used. For example, $\mathrm{KCl}$ elicits a sustained response, whereas the response to $\mathrm{NH}_{4} \mathrm{Cl}$ ceases before the stimulus is rinsed from the epiglottis. We have therefore measured two parameters:

(1) Presence or absence of a chemical response. A chemical response was defined as an increase in average frequency during any five sequential seconds of the stimulation period that exceeded the mean plus two standard deviations of the spontaneous activity rate.

(2) Response pattern. The variation with time of the response frequency for each stimulus.

\section{RESULTS}

\section{Presence or absence of a chemical response}

For both lamb and ewe SLN units, $\mathrm{KCl}$ was the most effective chemical stimulus, since $97 \%$ and $100 \%$ of fibers, respectively, responded to this chemical. For illustration, therefore, we ranked all fibers from lambs and ewes in order of the decreasing maximum response frequency to $\mathrm{KCl}$ (Fig. 2). Of the other salts, $\mathrm{NH}_{4} \mathrm{Cl}$ was the next most effective epiglottal stimulus $(73 \%$ of lamb and $90 \%$ of ewe fibers responded). The other two salts were relatively much less effective: for $\mathrm{NaCl}, 33 \%$ (lamb) and $41 \%$ (ewe), and for $\mathrm{LiCl}, 17 \%$ (lamb) and $28 \%$ (ewe) of fibers responded.

The most effective of the two acids was $\mathrm{HCl}(80 \%$ of lamb, $76 \%$ of ewe fibers responded); citric acid elicited a response from only $37 \%$ (lamb) and $38 \%$ (ewe) of fibers. Distilled water was more effective as an epiglottal stimulus than citric acid since $50 \%$ and $48 \%$ of the units, respectively, responded.

In summary, $\mathrm{KCl}, \mathrm{NH}_{4} \mathrm{Cl}$ and $\mathrm{HCl}$ are very effective stimuli for the epiglottis based on the proportion of fibers that respond. Water is effective for about half of the fibers, whereas citric acid, $\mathrm{NaCl}$ and $\mathrm{LiCl}$ are much less effective. Since we searched for single chemosensitive fibers using $\mathrm{KCl}, \mathrm{NH}_{4} \mathrm{Cl}$ and water, the large proportion of fibers responding to $\mathrm{KCl}$ and $\mathrm{NH}_{4} \mathrm{Cl}$ might be attributable to a search bias. However, as noted, water was also used as a search stimulus, yet only about $50 \%$ of all units responded. Furthermore, in whole nerve and multiunit recordings from the SLN we have found a similar order of relative effectiveness for the same stimuli used in this study ${ }^{5}$. Therefore, these single units reflect the general chemosensitive fiber population of the SLN.

\section{Response patterns}

The response patterns of all fibers during stimulation of the epiglottis with each stimulus are presented in Figs. 3 and 4. These responses have been ranked in order of the decreasing maximum response frequency for each chemical and have been separated into lamb and ewe units, for clarity. It is apparent that characteristic patterns of neural response are produced by each chemical. Responses to $\mathrm{KCl}$ stimulation tend to accelerate to a maximum frequency and then adapt to a lower frequency which is sustained until the epiglottis is rinsed (Fig. 3). In contrast, $\mathrm{NH}_{4} \mathrm{Cl}$ typically produces a short duration, high frequency response which adapts to spontaneous levels after about $5 \mathrm{~s}$, long before the epiglottis is rinsed. The response patterns produced by $\mathrm{NaCl}$ and $\mathrm{LiCl}$ are variable. $\mathrm{NaCl}$ produces a continuously increasing response frequency which is especially prominent in the ewe units. No particular pattern is observed for the relatively few fibers responding to $\mathrm{LiCl}$.

The response to both acid stimuli $(\mathrm{HCl}$ and citric acid) is typically an initial high frequency discharge followed by a lower frequency, which then increases again until the epiglottis is rinsed (Fig. 4). Distilled water produces a variety of response patterns. Some units respond to distilled water with a profile similar to that for $\mathrm{HCl}$, while others show a progressive increase in frequency throughout the stimulation period. 


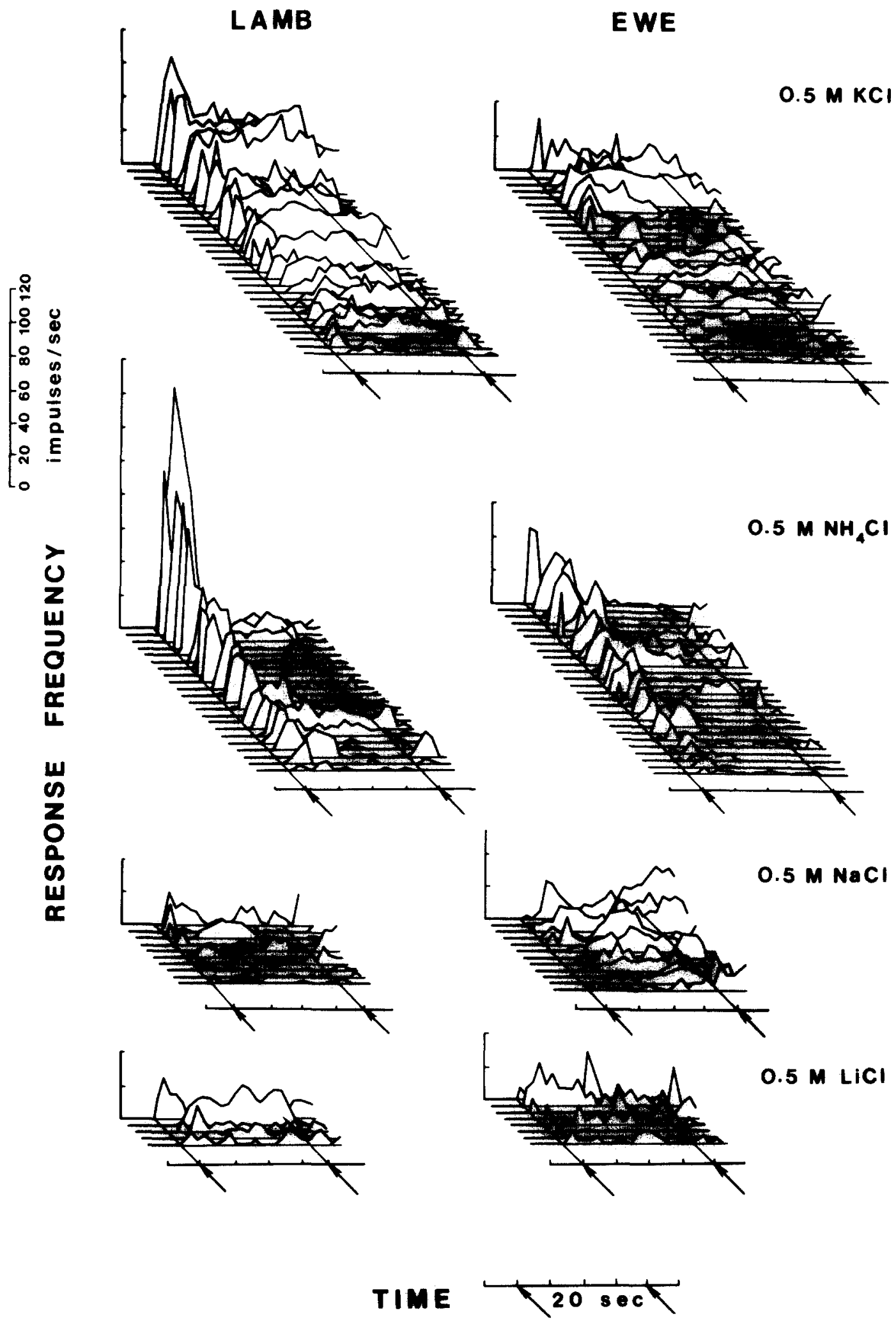

Fig. 3. Frequency-time histograms for responses from lamb and ewe single fibers to 4 salts. Responses are arranged in order of decreasing maximum frequency for each chemical. The spontaneous activity and response produced by flowing the stimulus have been subtracted. In general. similar response patterns are elicited by a particular stimulus. 
LAMB

$\left[\begin{array}{cc}0 & 0 \\ 0 & 0 \\ 0 & 0 \\ -9 & 8 \\ 0 & \frac{0}{3} \\ -0 & 0 \\ 0 & \underline{0}\end{array}\right.$

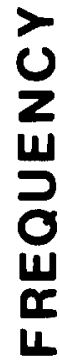

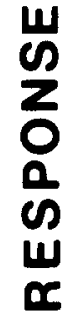
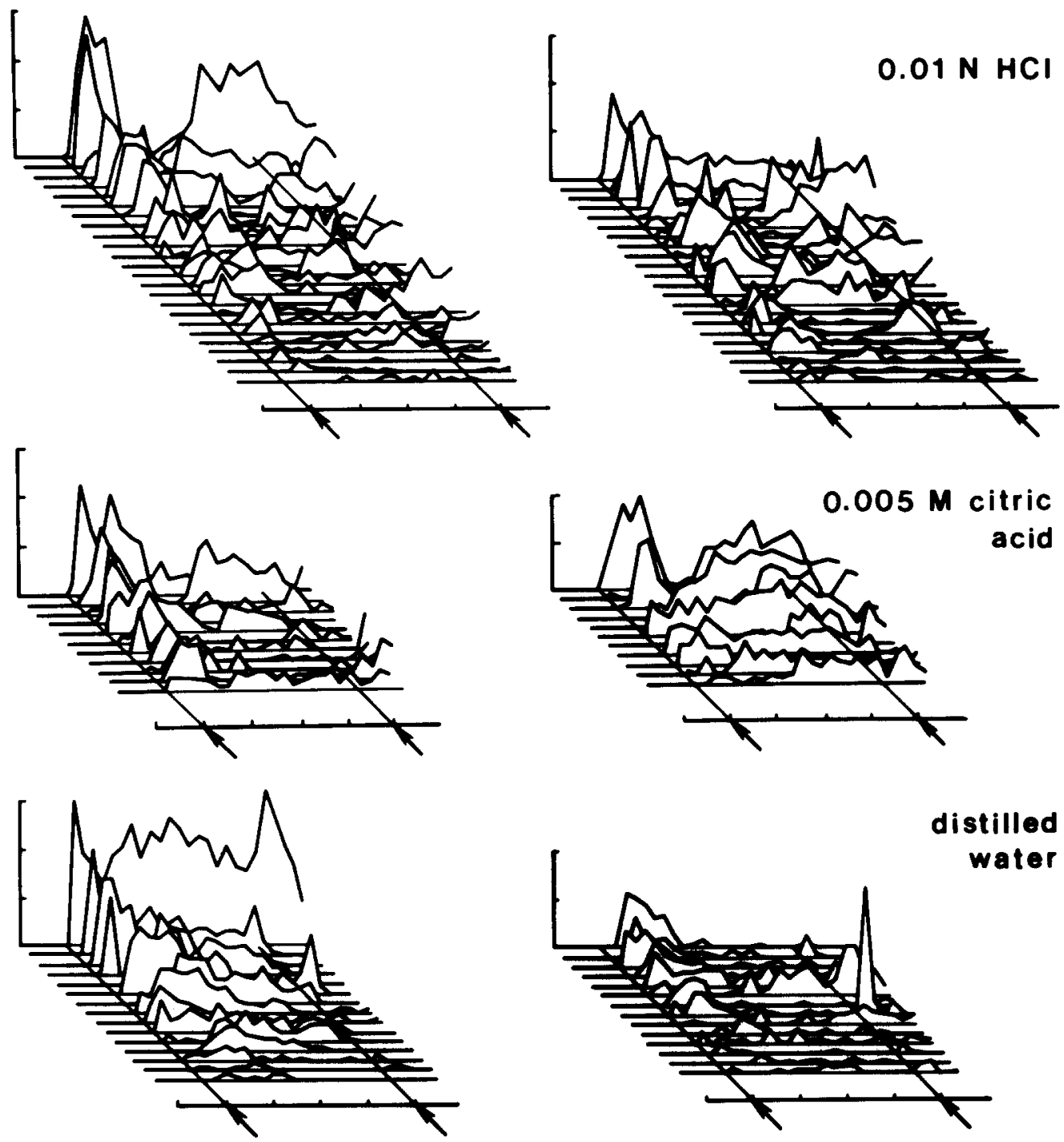

TIME

\section{$0.01 \mathrm{~N} \mathrm{HCI}$}

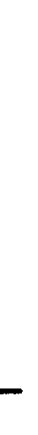

EWE 


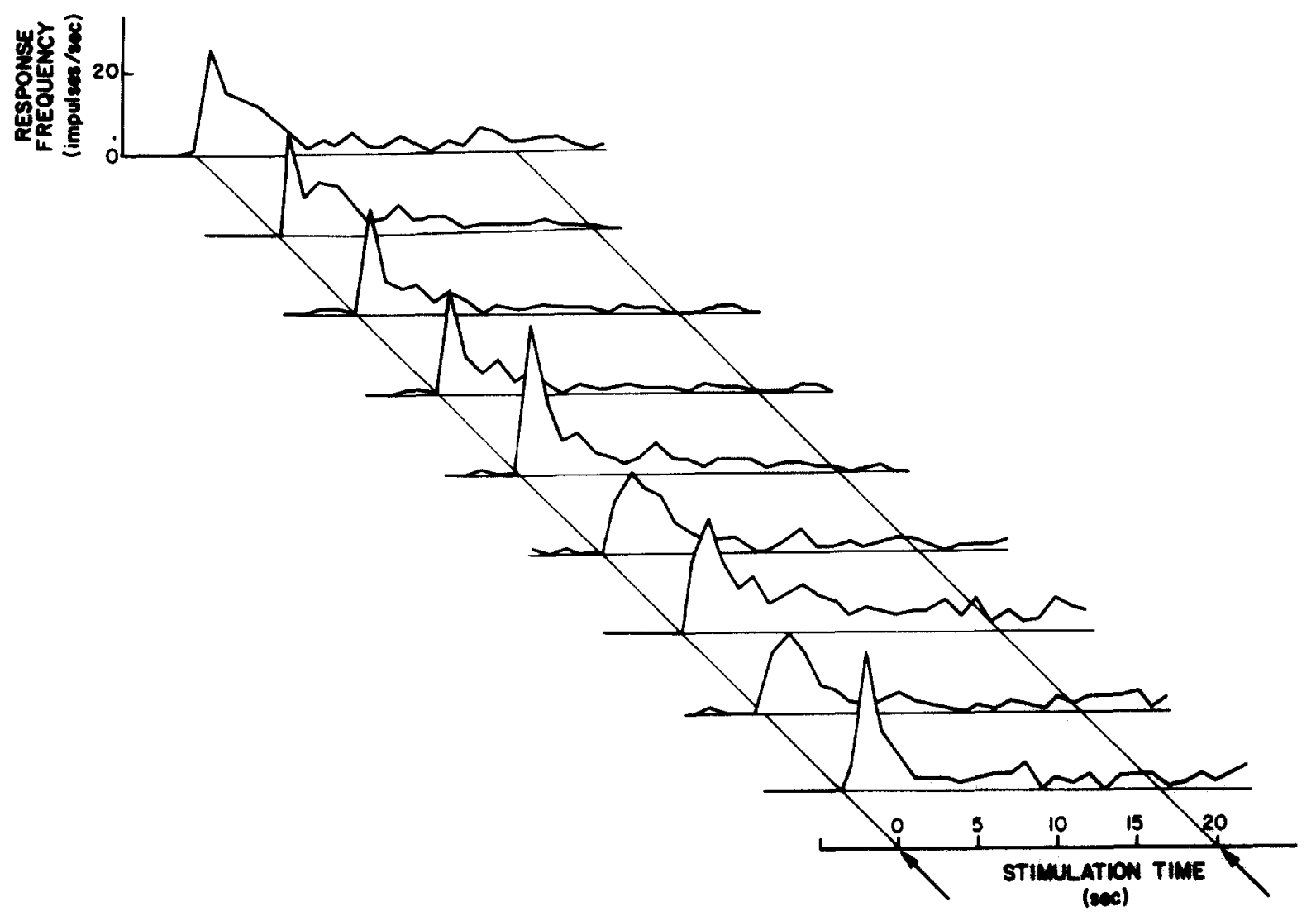

Fig. 5. Responses recorded from a single fiber during repeated stimulation of the epiglottis with $\mathrm{KCl}$. Other stimuli were applied between $\mathrm{KCl}$ stimulation periods, and the time span between the first and last $\mathrm{KCl}$ application was about 45 min. The responses demonstrate that $\mathrm{KCl}$ consistently elicits a similar response pattern over a prolonged time period.

in response patterns for one chemical across fibers, it is still obvious that the patterns can be quite variable. Therefore, a quantitative analysis is essential to learn whether individual chemicals do, in fact, elicit different response patterns.

We began by using statistical analyses to determine whether responses from lamb SLN fibers could be combined with those from ewe fibers for study of response patterns. Profile analysis was applied to determine whether the general response pattern for each chemical was similar for lambs and ewes. This analysis demonstrated that for each chemical stimulus the response pattern in lambs is parallel to that in ewes $(P>0.10)$. However, although the response patterns are parallel they are not always of the same magnitude. The response profiles for $\mathrm{NH}_{4} \mathrm{Cl}, \mathrm{KCl}$, $\mathrm{NaCl}$ and $\mathrm{H}_{2} \mathrm{O}$ are at overall higher frequencies for lambs than ewes $(P<0.10)$, but responses for $\mathrm{HCl}$ and citric acid are of similar magnitudes $(P>$
$0.10)$. Therefore the shapes of the response profiles do not change with age; however, there may be differences in the frequencies of the responses to some chemicals. Since for each chemical, response patterns were similar for lambs and ewes, we combined all units for further statistical analysis.

Responses recorded from one single fiber to a series of chemical stimuli are not independent. Therefore, to learn whether one chemical elicited a different response pattern from every other chemical, responses for all possible pairs of stimuli were compared for each individual unit. For these comparisons, the difference in response frequency between each pair of chemicals was calculated for every second of the stimulation period. Thus, if response patterns to any pair of stimuli are similar, constant differences in frequency throughout the entire stimulation period should emerge.

For example, consider the graphs of response fre- 
quencies from one single fiber for $\mathrm{NaCl}$ compared with $\mathrm{LiCl}$, and $\mathrm{NaCl}$ compared with $\mathrm{NH}_{4} \mathrm{Cl}$, in Fig. 6 . Throughout the response period, a relatively constant set of differences between $\mathrm{NaCl}$ and $\mathrm{LiCl}$ is found because the response frequency patterns are parallel. Thus, the function for the difference score over time is flat. For $\mathrm{NaCl}$ versus $\mathrm{NH}_{4} \mathrm{Cl}$ the difference score varies across time because the patterns are not similar.

Once difference profiles are calculated for all pairs of stimuli within each fiber, comparisons can be made across fibers. The results of this analysis are presented in Table $I$. The pairs of chemicals that have dissimilar response patterns $(P<0.10)$ are indicated in the table, with the significance level for the pairwise comparison (one sample profile analysis ${ }^{26}$ ). Dashed lines indicate parallel or similar responses; e.g., the patterns for $\mathrm{NaCl}$ and $\mathrm{LiCl}, \mathrm{NaCl}$ and citric acid, are similar, as are those for $\mathrm{LiCl}$ and water,
TABLE I

\section{Chemical pairs that elicit different response patterns}

For each stimulus pair that produce significantly different patterns, the $P$ value is presented in the table. A dash indicates that the stimuli elicit similar (parallel) response patterns $(P>$ 0.10 ).

\begin{tabular}{lllllll}
\hline & $\mathrm{NH}_{4} \mathrm{Cl}$ & $\mathrm{NaCl}$ & $\mathrm{LiCl}$ & $\mathrm{H}_{2} \mathrm{O}$ & $\mathrm{HCl}$ & cit \\
\hline $\mathrm{KCl}$ & 0.000 & 0.001 & 0.002 & 0.060 & 0.079 & 0.016 \\
$\mathrm{NH}_{4}$ & & 0.000 & 0.001 & 0.027 & 0.007 & 0.001 \\
$\mathrm{NaCl}$ & & & - & 0.084 & 0.061 & - \\
$\mathrm{LiCl}$ & & & & - & 0.024 & - \\
$\mathrm{H}_{2} \mathrm{O}$ & & & & & 0.004 & - \\
$\mathrm{HCl}$ & & & & & & - \\
\hline
\end{tabular}

$\mathrm{LiCl}$ and citric acid. Similar response patterns are also produced by the two acids. The response pattern to water is similar to that for citric acid, but not $\mathrm{HCl}$.

From this statistical analysis, therefore, it can be concluded that peripheral neural response patterns
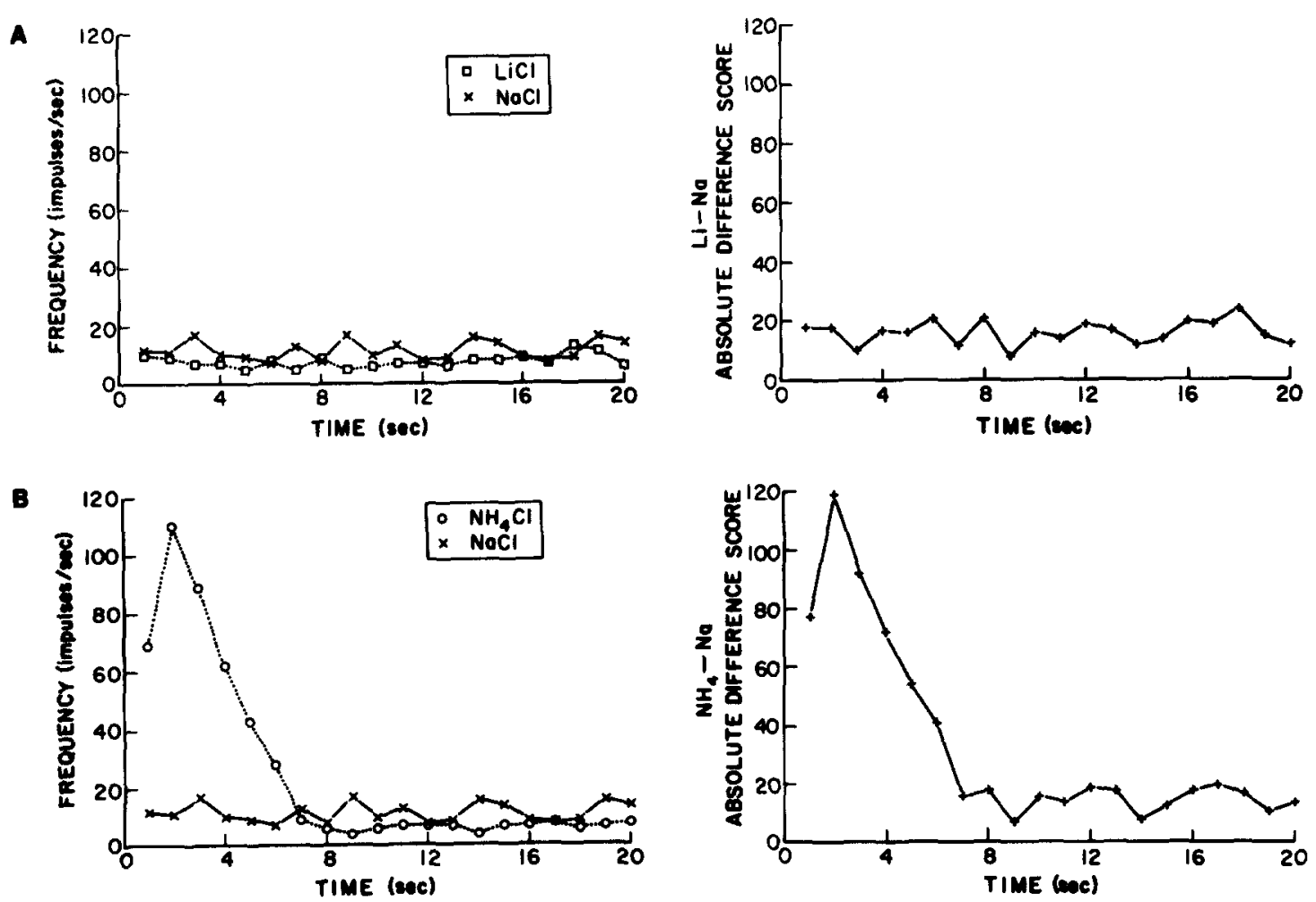

Fig. 6. Graphs to illustrate the comparison of response patterns from one single fiber for two pairs of stimuli: (A) $\mathrm{NaCl}$ versus $\mathrm{LiCl}$, and (B) $\mathrm{NaCl}$ versus $\mathrm{NH}_{4} \mathrm{Cl}$. On the left side of the figure the responses for each stimulus pair are represented as variations in response frequency with time. On the right side the absolute difference scores between the pairs of chemicals are presented. Note that there is a constant difference score between $\mathrm{NaCl}$ and $\mathrm{LiCl}$ indicating that these chemicals produce response patterns that are parallel. The difference score between $\mathrm{NaCl}$ and $\mathrm{NH}_{4} \mathrm{Cl}$ varies with time indicating that these two chemicals do not have parallel response patterns. 

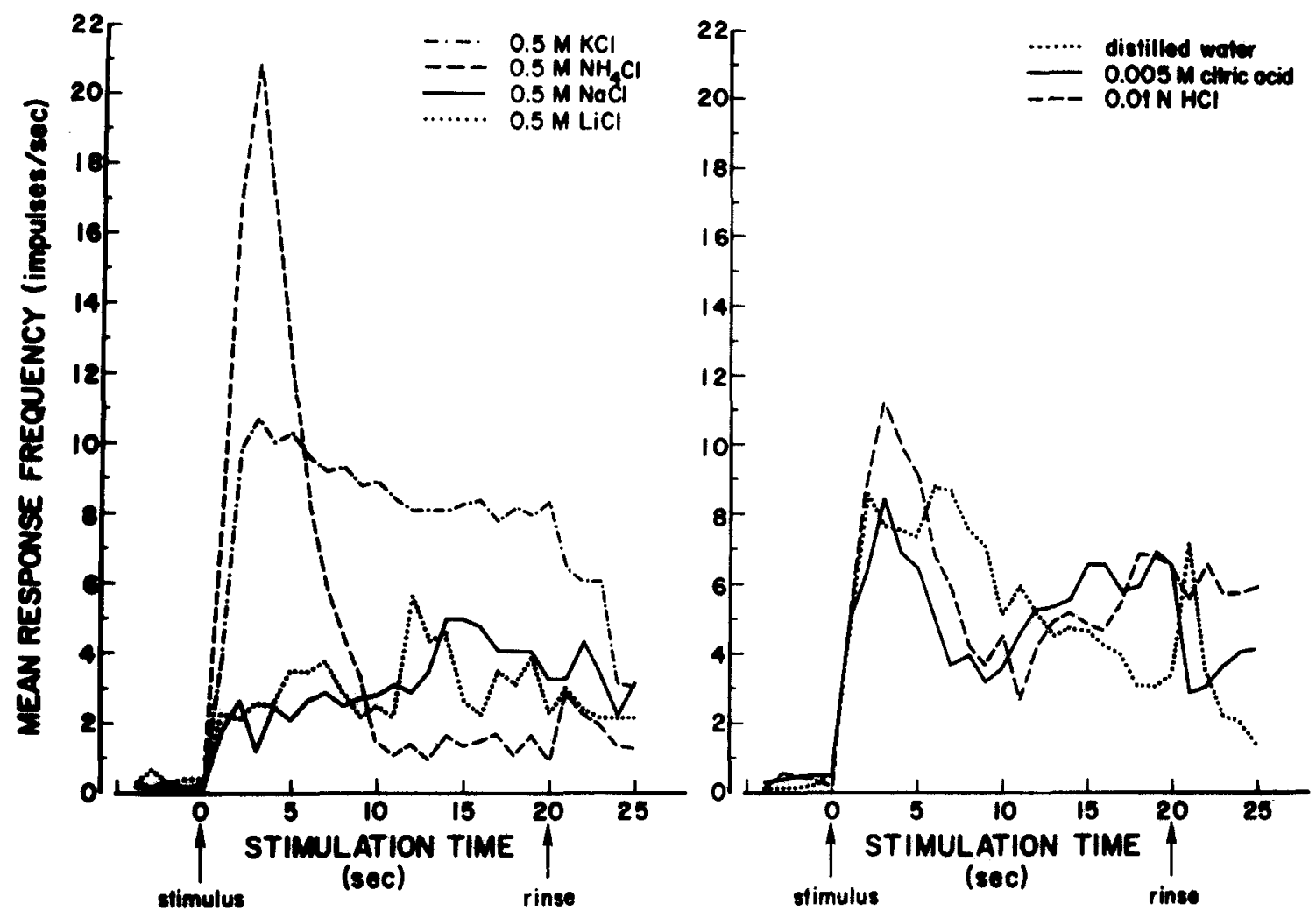

Fig. 7. Average response patterns across single fibers for all chemical stimuli. Note the differences and similarities between the response patterns produced by the various stimuli.

over time are sufficient to discriminate among salts $\left(\mathrm{NH}_{4} \mathrm{Cl}\right.$ from $\mathrm{KCl}, \mathrm{NaCl}$ or $\mathrm{LiCl}$ ), between some salts and acids, and between some salts and water, during stimulation of the epiglottis. The general patterns which are summarized as average response profiles in Fig. 7, are similar to the summated whole SLN responses 5 indicating that the single fiber recordings are a representative sample of the whole nerve.

Although a demonstration that the patterns are statistically different does not mean that they are significant to the nervous system, the existence of differences is provocative. If pattern differences are ignored, average response frequency would have to be sufficient to discriminate among chemicals. Yet average frequencies are not very different for some of the chemicals we used. For example, average maximum response frequencies across all fibers in ewes are: $\mathrm{KCl}=18, \mathrm{NH}_{4} \mathrm{Cl}=19, \mathrm{HCl}=18$, and citric acid $=$ $16 \mathrm{impulses} / \mathrm{s}$. It is difficult to understand how these responses could be distinguished from each other on the basis of frequency alone. Yet the $\mathrm{KCl}$ response pattern is different from those of the other 3 stimuli (Table $\mathrm{I}$ ), as is the $\mathrm{NH}_{4} \mathrm{Cl}$ response pattern.

\section{DISCUSSION}

\section{Chemosensitive response patterns}

Several chemical stimuli elicit neural responses from the SLN that are distinguishable from each other as frequency patterns over time. For example, $\mathrm{NH}_{4} \mathrm{Cl}$ elicits a transient discharge while $\mathrm{KCl}$ produces a response that is sustained during the entire stimulation period. $\mathrm{NaCl}$ and $\mathrm{LiCl}$ do not always produce a response, but when a response occurs, the impulse discharge increases gradually with $\mathrm{NaCl}$ but is variable with $\mathrm{LiCl}$ stimulation. The acids produce an initial high frequency response which then declines, and is eventually followed by an increase. Water on the epiglottis elicits a variety of response profiles, with some units having a profile similar to that produced by acids while others resemble a salt pattern. The results therefore demonstrate that different chemicals 
applied to the epiglottis can produce discharge patterns characteristic of that chemical. Statistical analysis of differences in response frequencies for pairs of chemicals over time demonstrates that these patterns are in fact distinguishable. Furthermore, for several chemicals that elicit nearly equal average maximum response frequencies, response patterns are different and may provide the means for neural discrimination.

Response patterns from chemosensitive fibers innervating lingual taste buds were described qualitatively by Fishman ${ }^{9}$ over 20 years ago. He classified 5 types of response in rat chorda tympani fibers. These included a rapid initial response followed by a steady state activity, a steady state activity attained without a rapid initial burst, a rapid initial burst followed by a silent period followed by a return of activity, a gradual increase in activity to a maximum with a subsequent decline, and a rhythmic burst-like firing. There were some correlations between the stimuli used and the response profiles. Monovalent salts generally produced one kind of response, while divalent salts produced a different response profile. The bursting pattern was most often associated with sweet substances.

Since this report by Fishman ${ }^{9}$ there have been a few attempts to quantify the temporal response pattern in chemosensitive fibers with interspike interval histogram analysis ${ }^{15-17}$. However for many fibers an$\mathrm{d} /$ or chemicals the interspike interval distribution is random and it is generally not possible to correlate taste quality and temporal pattern with this analysis.

Others have questioned the need to study a prolonged period of the neural discharge because it has been shown that only a brief initial portion of the response is required to make a quality discrimination ${ }^{10,11}$. However, these results were based on responses to $0.3 \mathrm{M} \mathrm{NaCl}$, a concentration that is close to the receptor saturation level. It may take a longer time period for quality decisions at lower concentrations and other qualities need not necessarily be discriminated in so short a time. Intensity judgements may require a longer stimulation period, also. In addition, the central nervous system may use longer processing times in order to take into account spatial and temporal properties of the stimulating condition. Thus, although it is apparently possible in certain circumstances to make a quality decision using only the initial portion of the response, it would be premature at this time to dismiss the rest of the response period as having no significance in transmitting information concerning sensory properties of the stimulus.

\section{Response patterns and upper airway reflexes}

The discovery of specific response patterns in SLN chemosensitive afferents may be important in understanding upper airway reflexes. The current theory of the control of these reflexes proposes that a 'center' in the brainstem can initiate precise spatio-temporal muscle contractions in response to a peripheral input $^{8}$. Furthermore, it is suggested that the center has an afferent portal which functions to decode the input to produce the appropriate output. Thus, each reflex is associated with a uniquely coded input. The code cannot be restricted to a specific receptor type since there are too many reflex outputs for too few receptor types. It is likely, therefore, that temporal and spatial patterning are important in coding for different stimuli. There are few data on the temporal aspects (and none on the spatial aspects) of the discharge pattern from upper airway receptors. Recent reports provide detailed latency and discharge duration characteristics ${ }^{12.23}$, but the present paper is the first to describe variations in discharge frequency with time, i.e. the response pattern.

There are few data on the use of chemical stimuli to produce upper airway reflexes. Johnson et al.13 were able to initiate swallowing and apnea in lambs by using various chemical stimuli applied to the larynx. Sucrose, glucose, $\mathrm{HCl}$, quinine hydrochloride dissolved in water, and water alone, initiated apnea and swallowing. Sodium chloride at several concentrations (including isotonic) was ineffective in producing either swallowing or apnea. Shingai and Shimada ${ }^{20}$ obtained similar results in the rabbit. $\mathrm{NaCl}$ was generally ineffective, or only effective at low concentrations after a long latency. However, water applied to the larynx was an effective stimulus in producing a swallow.

These results may be compared with the present study in which $\mathrm{NaCl}$ was one of the least effective stimuli. It should also be noted that $\mathrm{NaCl}$ produces its maximum response some time after stimulus application, which correlates well with the long latencies reported in the rabbit for the production of swallowing by $\mathrm{NaCl}^{20}$. Of the other salts used by Shingai and Shi- 
mada ${ }^{20}$, several were effective in producing swallowing while the remainder were similar to $\mathrm{NaCl}$. Sucrose and quinine hydrochloride dissolved in water induced swallowing, as in the study of Johnson et al. ${ }^{13}$. However, when dissolved in saline they were ineffective, indicating that it was the water and not the sucrose or quinine hydrochloride that was initiating the reflex activity.

The other stimuli used by Shingai and Shimada 20 were different from the ones used in the present study. However, they did use acid stimulation (acetic acid. $\mathrm{pH} 2.60$ ) which elicited repetitive reflex swallowing. This may be compared with the results of the present study in which acids were effective stimuli when applied to the epiglottis.

These studies suggest a relationship between chemical stimuli and reflex activity. The present study extends these findings to demonstrate a correspondence between stimulus and response pattern in the SLN. It is possible, therefore, that the response patterns represent a neural code that when deciphered by the portal of the 'swallowing center' initiates different reflex activities.

\section{Comparison of sheep and cat $S L N$ responses}

Responses from SLN fibers in cat have been recorded also during chemical stimulation of the epiglottis ${ }^{23}$. In both cat and sheep, $\mathrm{KCl}$ was the most effective of the salt stimuli used, and $\mathrm{NH}_{4} \mathrm{Cl}$ was next most effective. $\mathrm{NaCl}$ and $\mathrm{LiCl}$, however, which frequently elicited responses from sheep SLN, were not effective stimuli in the cat; virtually no fibers responded. $\mathrm{NaCl}$ and $\mathrm{LiCl}$ are also rather ineffective stimuli for cat lingual taste buds. Acids and water as epiglottal stimuli were similar in both species, with an order of decreasing effectiveness of $\mathrm{HCl}>\mathrm{H}_{2} \mathrm{O}$ $>$ citric acid.

Although a detailed analysis of response patterns was not made for cat SLN fibers, some comparative statements can be made. Notable in both species is the very high frequency, rapidly adapting response to $\mathrm{NH}_{4} \mathrm{Cl}$ on the epiglottis. In the cat, $\mathrm{HCl}$ and citric acid also elicited responses that adapted to baseline before the chemical was rinsed. Water elicited most variable response patterns in cat, as in sheep. Therefore, these properties of SLN fiber discharge patterns are similar in two widely different mammalian species.
TABLE II

Order of effective stimulation for salts on sheep tongue and epiglottis

\begin{tabular}{lll}
\hline Nerve & Region stimulated & Chemical stimulus \\
\hline Chorda tympani & anterior tongue & $\mathrm{NH}_{4}=\mathrm{Na}=\mathrm{Li}>\mathrm{K}$ \\
Glossopharyngeal & $\begin{array}{l}\text { posterior tongue } \\
\text { epiglottis }\end{array}$ & $\mathrm{NH}_{4}>\mathrm{K}>\mathrm{Na}=\mathrm{Li}$ \\
Superior laryngeal & $\mathrm{K}^{2} \mathrm{NH}_{4}>\mathrm{Na}=\mathrm{Li}$ \\
\hline
\end{tabular}

Comparison of sheep SLN, chorda tympani and glossopharyngeal nerve chemosensitive responses

Taste buds located on the anterior and posterior tongue and epiglottis of sheep respond differently to the 4 salts, $\mathrm{NH}_{4} \mathrm{Cl}, \mathrm{KCl}, \mathrm{NaCl}$ and $\mathrm{LiCl}^{5}$. Responses from the chorda tympani nerve during stimulation of the anterior tongue have an initial dynamic and later, sustained, adapted phase for all salts. The glossopharyngeal nerve responds to these salts with a similar general pattern. Thus, the very rapidly adapting SLN response to $\mathrm{NH}_{4} \mathrm{Cl}$ stimulation of the epiglottis is not observed for the tongue.

The order of effective stimulation also changes for each of the receptive fields supplied by the 3 nerves (Table II). $\mathrm{NaCl}$ and $\mathrm{LiCl}$, extremely effective anterior tongue stimuli, become progressively less effective for the posterior tongue and epiglottis. Interestingly, in the sheep, water is an effective stimulus for the epiglottis, but not for the tongue. The structure of the taste buds in these 3 locations appears similar by light microscopy so that the same basic taste bud morphology has been adapted to respond differently depending on its location and its ultimate functional role.

In conclusion, studies of responses from SLN fibers in sheep have demonstrated that the epiglottis, like the tongue, is broadly chemosensitive, responding to a variety of salts, acids, and water. From quantitative analysis of response frequency throughout the stimulation period, it is apparent that different chemicals elicit neural activity that can be distinguished on the basis of response patterns. These patterns may provide information to central nervous system areas such as the 'swallowing center' about which chemical is present in the upper airway.

\section{ACKNOWLEDGEMENTS}

This research was supported in part by N.I.H. 
Grant DE 05728 to R.M.B and C.M.M., and Research Career Development Award, DE 00066 to C.M.M. We thank Mr. K. Guire, School of Public

\section{REFERENCES}

1 Andrew, B. L., A functional analysis of the myelinated fibres of the superior laryngeal nerve in the rat, $J$. Physiol. (Lond.), 133 (1956) 420-432.

2 Beidler, L. M., A theory of taste stimulation, J. gen. Physiol., 38 (1954) 133-139.

3 Boushey, H. A., Richardson, P. S., Widdicombe, J. G. and Wise, J. C. M., The response of laryngeal afferent fibres to mechanical and chemical stimuli, J. Physiol. (Lond.), 240 (1974) 153-175.

4 Bradley, R. M., Tapping into the brain, Microcomputing, 6 (1982) 72-79.

5 Bradley, R. M., The role of epiglottal and lingual chemoreceptors: a comparison. In J. E. Steiner and J. R. Ganchrow (Eds.), Determination of Behaviour by Chemical Stimuli, IRL Press, London 1982, pp. 37-45.

6 Bradley, R. M., Cheal, M. L. and Kim, Y. H., Quantitative analysis of developing epiglottal taste buds in sheep, $J$. Anat., 130 (1980) 25-32.

7 Doty, R. W., Influence of stimulus patterns on reflex deglutition, Amer. J. Physiol., 166 (1951) 142-158.

8 Doty, R. W., The concept of neural centers. In J. C. Fentress (Ed.), Simpler Networks and Behavior, Sinauer Associates, Sunderland MA, 1976, pp. 251-265.

9 Fishman, I. Y., Single fiber gustatory impulses in rat and hamster, J. Cell. comp. Physiol., 49 (1957) 319-334.

10 Halpern, B. P. and Tapper, D. N., Taste stimuli: quality coding time, Science, 171 (1971) 1256-1258.

11 Halpern, P. B. and Marowitz, L. A., Taste responses to lick duration stimuli, Brain Research, 57 (1973) 473-478.

12 Harding, R., Johnson, P. and McClelland, M. E., Liquidsensitive laryngeal receptors in the developing sheep, cat and monkey, J. Physiol. (Lond.), 277 (1978) 409-422.

13 Johnson, P., Robinson, J. S. and Salisbury, D. M., The onset and control of breathing after birth. In K. S. Comline, D. W. Cross, G. S. Dawes and P. W., Nathanielsz (Eds.), Foetal and Neonatal Physiology, Cambridge University Press, Cambridge, 1973, pp. 217-221.

14 Miller, A. J., Characteristics of the swallowing reflex in-
Health, for expert assistance with data analysis and Dr. Bruce E. Bradley for assistance in some of the neurophysiological recordings.

duced by peripheral nerve and brain stem stimulaton, Exp. Neurol., 34 (1972) 210-222.

15 Mistretta, C. M., A quantitative analysis of rat chorda tympani fiber discharge patterns, In D. Schneider (Ed.), Olfaction and Taste $I V$, Wissenschaftliche Verlagsgesellschaft, Stuttgart, 1972, pp. 294-300.

16 Nagai, T. and Ueda, K., Stochastic properties of gustatory impulse discharges in rat chorda tympani fibers, J. Neurophysiol., 45 (1981) 574-592.

17 Ogawa, H., Sato, M. and Yamashita, S., Variability in impulse discharges in rat chorda tympani fibers in response to repeated gustatory stimulations, Physiol. Behav., 11 (1973) $469-479$.

18 Sato, T., Site of gustatory neural adaptation, Brain $R e$ search, 34 (1971) 385-388.

19 Sato, T., Multiple sensitivity of single taste cells of frog tongue to 4 basic taste stimuli, J. Cellular Physiol., 80 (1972) 207-218.

20 Shingai, T. and Shimada, K., Reflex swallowing elicited by water and chemical substances applied in the oral cavity, pharynx, and larynx of the rabbit, Jap. J. Physiol., 26 (1976) 455-469.

21 Smith, D. V. and Bealer, S. L., Sensitivity of the rat gustatory system to the rate of stimulus onset, Physiol. Behavior, 15 (1975) 303-314.

22 Smith, D. V., Steadman, J. W. and Rhodine, C. N., An analysis of the time course of gustatory neural adaptation in the rat, Amer. J. Physiol., 229 (1975) 1134-1140.

23 Stedman, H. M., Bradley, R. M., Mistretta, C. M. and Bradley, B. E., Chemosensitive responses from the cat epiglottis, Chem. Senses, 5 (1980) 233-245.

24 Storey, A. T., A functional analysis of sensory units innervating epiglottis and larynx, Exp. Neurol., 20 (1968) $366-383$.

25 Storey, A. T. and Johnson, P., Laryngeal water receptors initiating apnea in the lamb, Exp. Neurol., 47 (1975) 42-55.

26 Timm, N. H., Multivariate Analysis with Applications in Education and Psychology, Brooks Cole, Monterey, CA, 1975. 